\title{
Comparative evaluation of microtensile bond strength of resin based composite to dentin using an experimental neat-resin dentin bonding agent with ethanol -wet bonding technique - an invitro study
}

\author{
Nandini Pugal*, Dhanavel Chakravarthy, Padmaraj SN, Vijayaraja, Ambily Jayadevan, Limly Bal and Pugazhenthiran I \\ Department of conservative dentistry and endodontics, Indira Gandhi institute of dental sciences, Sri Balaji Vidhyapeeth University, Pondicherry, India
}

\section{Introduction}

With the introduction of acid etching by Buonocore, a predictable bond strength of $20-25 \mathrm{MPa}$ was achieved by enamel bonding to composite resin. However, bonding to dentin posed challenges due to the organic nature and moisture content. This resulted in the evolution of dentin bonding agents [1]. Acid etching and drying the surface resulted in collapse of the collagen fibrils hindering in the penetration of the resin. Therefore, water wet bonding was proposed by Kanca, et al. This technique enabled the penetration of resin into the dentinal collagen resulting in a hybrid layer [2].

The water from the dentin however had to be removed for the penetration of the hydrophobic resin. This led to the development of the etch and rinse adhesives that contained solvents such as ethanol and acetone that acted as water chasers. This also contained a combination of hydrophilic and hydrophobic monomers. The hydrophilic monomers, HEMA, enabled wetting of the bonding agent to the moist dentin and ethanol/ acetone helps in driving away the moisture, subsequently enabling the hydrophobic BIS GMA resin to penetrate the collagen [3].

The water wet bonding and use of etch and rinse system though produced good bonding, they resulted in degradation over time. Two types of degradation results such as hydrolytic degradation and enzymatic degradation. If the moisture is not completely removed from the interphase by the solvents, the hydrophilic monomer HEMA undergoes a hydrolytic degradation due to water sorption. There is also a risk for phase separation of hydrophobic resin (BIS-GMA) from hydrophilic resin monomer. In addition, the host derived matrix metalloproteinases (MMP) gets activated by the etch and rinse systems resulting in degradation of the collagen [4].

To overcome the deleterious effect of residual moisture in water wet bonding and, the use of hydrophilic monomers in the dentin bonding systems, the Ethanol Wet Bonding system was developed. This is based on the histological specimen preparation where ascending grades of alcohol is used to desiccate the tissue specimens. The moist dentin surface is saturated with absolute alcohol to remove the moisture. A hydrophobic resin monomer has been found to effectively bond to this dried surface [5-7]. Use of ascending grades of ethanol was time consuming. Thus a simplified method of using $100 \%$ ethanol for 60 seconds have been evaluated [8]. Studies have been done in this concept to assess the bond durability as well as to compare the effect of certain MMP inhibitors with the ethanol wet bonding technique on enzymatic degradation [9-11]. The reports of these studies are promising towards longer durability and MMP inhibition. Studies have been done that assesses the micro tensile bond strength of ethanol wet bonding technique with commercially available dentin bonding agents in enamel, dentin and carious dentin $[8,12,13]$.

This study aims to evaluate the immediate and delayed micro tensile bond strength of the resin composite bonded to dentin with ethanol wet bonding method.

\section{Materials and methodology}

This research is an experimental study based on a comparative evaluation of microtensile bond Strength of resin-based composite to dentin using an experimental neat-resin dentin bonding agent with ethanol -wet bonding technique - An Invitro study .Sample preparation were done in Department of Conservative Dentistry \& Endodontics, IGIDS, Puducherry and Bond strength was evaluated by using universal testing machine in CIPET (Central Institute of Plastic and Engineering Technology), Guindy, Chennai.

The study was approved by the Institutional review board on 01.12.2016 Ref no -

IGIDSIRB2016NDP12PGNDCDE and Institutional Ethical committee on 16.12.16 Ref no -

\section{IGIDSIEC2016NDP12PGNDCDE}

Non carious extracted third molars were collected in IGIDS, Puducherry which fulfilled the inclusion and exclusion criteria were selected. The following inclusion criteria were used for tooth sample collection: Freshly extracted impacted mandibular third molar, Without carious lesions, Without cracks or fractures during extraction procedure. Carious/ non-carious lesions/ traumatic fractures if present, the teeth are excluded.

40 freshly extracted third molars were used in this study. The sample size was determined in the pilot study by using mean and standard deviation and found to be 40 .

*Correspondence to: Nandini Pugal MDS, Department of conservative dentistry and endodontics, Indira Gandhi institute of dental sciences, Pondicherry-607402, India, E-mail: nandini26588@gmail.com

Received: March 12, 2019; Accepted: March 21, 2019; Published: March 25, 2019 
Pugal N (2019) Comparative evaluation of microtensile bond strength of resin based composite to dentin using an experimental neat-resin dentin bonding agent with ethanol -wet bonding technique - an invitro study

The samples were divided into two groups and Each group were divided into two subgroups in which each subgroup will contain 10 samples. Each tooth can yield 10 composite-resin beam of $1 \times 1 \times 6 \mathrm{~mm}^{3}$. Equals to 100 beams per subgroup.

Sample size calculated with mean and SD of micro tensile bond strength in MPa obtained from Sadek, et al for the subgroup of 24 hours microtensile bond strength [14]. Sample size calculated with $\mathrm{G}^{\star}$ Power 3.1.9.2, Germany. Samples calculated was 95 per subgroup. Approximated to 100 per subgroup after accounting for $10 \%$ sample loss.

Forty freshly extracted, intact, non-carious, impacted third molars were cleaned and stored in distilled water. Informed consent was obtained from the patients before extraction.

\section{Sample preparation}

The roots were resected at the cervical region with the diamond disc under water coolant. The clinical crown was trimmed below the CEJ, with the diamond disc under water coolant, exposing a flat middle dentinal surface. The teeth was fixed to an acrylic block with cyanoacrylate resin. 180 grit silicon carbide paper was used to polish the surface to create a dentinal smear layer [11].

\section{Sample allocation}

Samples were divided into two groups $(n=20)$ per group. Group1ethanol wet bonding method primed with $50 \mathrm{wt} \%$ of experimental neat resin monomer and $50 \mathrm{wt} \%$ of absolute ethanol bonded with neat monomer. Group 2:water wet bonding method primed and bonded with ethanol based etch and rinse adhesive (3M Adaper single Bond 2)

\section{Preparation of experimental neat resin}

A co-monomer resin was prepared consisting of the following composition will be made $70 \%$ wt bisphenol A diglycidyletherdimethacrylate (BIS-GMA) (SIGMA-ALDRICH) $28.75 \%$ tetra-ethylene glycol dimethacrylate (TEGDMA) (SIGMAALDRICH) 0.25\% Camphorquinone (CQ) (SIGMA-ALDRICH) $1 \mathrm{wt} \%$ ethyl N, N-4 aminobenzoate (SIGMA-ALDRICH)

\section{Priming and bonding procedure}

All samples in both groups were acid etched with $35 \%$ phosphoric acid for $15 \mathrm{sec}$.

They were washed with distilled water. Blot dried with absorbent paper leaving the surface moist.

Group 1: bonding of resin composite in ethanol wet bonding $(n=20)$

The dentin surface was inverted in $2 \mathrm{ml}$ of $100 \%$ ethanol for $60 \mathrm{sec}$ (saturating the dentin with ethanol).

Excess ethanol was blot dried with absorbent paper $50 \mathrm{wt} \%$ neat resin and 50wt $\%$ absolute ethanol was applied to the dentin with fine microbrush in two thin coats and are agitated for 10 secs. The excess primer was evaporated with a chip blower for 10 secs. Experimental neat resin monomer was applied in the surface as an adhesive.

Light curing was done with LED curing at $600 \mathrm{mw} / \mathrm{cm}^{2}$. Resin composite (3M3SPE Filtek Z350 XT) build up was done in $2 \mathrm{~mm}$. increments in two increment to a height of $4 \mathrm{~mm}$. (fig 15). Each layer was light cured for 40 secs. Each tooth was sectioned into $1 \times 1 \times 6 \mathrm{~mm}^{3}$ sized composite-dentin beam by non-trimming method. Samples were stored in artificial saliva.
Group 2: Bonding of resin composite in water wet bonding $\operatorname{method}(n=20)$

Application of etch and rinse ethanol-based dentin bonding agent, 3M ADPER Single Bond 2, as per manufacturers instrumentation, to the etched, rinsed and blot dried dentin surface. Composite resin build up as mentioned in groups 1 will be done. Sectioned teeth were stored in artificial saliva as in group 1.

\section{Preparation of artificial saliva}

The artificial saliva is prepared by mixing $\mathrm{CaCl}_{2}(0.7)$-calcium chloride, $\mathrm{MgCl}_{2} 6 \mathrm{H}_{2} \mathrm{O}$ (0.2), $\mathrm{KH}_{2} \mathrm{PO}_{4}(4.0), \mathrm{KCL}$ (30), $\mathrm{NaN}_{3}(0.3)$, HEPES buffer. (4-(2hydroxyethyl)-1-piperazineethane sulfonic acid). The samples are stored in this at $37^{\circ} \mathrm{C}$. The solution is changed periodically.

\section{Microtensile bond strength testing}

Both groups 1 and 2 were subdivided into two groups:

sub group 1a: for immediate micro tensile bond strength evaluation $(\mathrm{n}=10)$ subgroup $1 \mathrm{~b}$ : for micro tensile bond strength evaluation after nine months of storage $(n=10)$ Group 2: sub group 2a: for immediate micro tensile bond strength evaluation $(\mathrm{n}=10)$ subgroup $2 \mathrm{~b}$ : for micro tensile bond strength evaluation after nine months of storage $(n=10)$.Each tooth was sectioned into $1 \times 1 \times 6 \mathrm{~mm}^{3}$ sized composite-dentin beam by non- trimming method. Ten beams from each tooth were selected for micro tensile bond strength. The beams were attached to the test apparatus with cyanoacrylate adhesive. The beams were stressed to fail under tension using a universal testing machine at a constant cross head speed of $1 \mathrm{~mm} / \mathrm{min}$. Fractographical analysis was made under SEM

(adhesive/cohesive/or mixed failure). Bond strength values were measured in $\mathrm{MPa}$.

\section{Statistical methods}

Descriptive Statistics: Mean and SD of the micro tensile bond strength in MPa. (Table 1 and 2)

According to the statistical analysis paired $t$ test were used

Std.deviation-WWB 24 hrs-3.0315

EWB-24hrs-5.5613

WWB-9months-1.4824

EWB 9 months -2.4097

After bond strength testing the samples were air dried, sputter coated with gold palladium and were seen under SEM, failure mode was identified. The microtensile bond strength values of water wet bonding and ethanol bonding. Control group 40 samples 400 samples were obtained in $\mathrm{MPa} n=400$

In WWB condition: For group 1 a control group, WWB-24 mean score is $21.46 \pm 3.03 \mathrm{MPa} W W B-9$ months is $18.81 \pm 1.45 \mathrm{MPa}$

In EWB group -Group 2 a -EWB-24 hrs mean is $54.47 \pm 5.56 \mathrm{MPa}$, EWB 9 months $40.8773 \pm 2.40 \mathrm{MPa}$

\section{Inferential statistics:}

Paired $t$ test is used to determine if there was difference between WWB and EWB 24hrs bond strength for both

WWB and EWB showed a mean value of $-33.011 \pm 6.56 \mathrm{MPa}$

9 months showed $-22.064 \pm 2.85 m p a(\mathrm{p}>0.005)-3$ 
Pugal N (2019) Comparative evaluation of microtensile bond strength of resin based composite to dentin using an experimental neat-resin dentin bonding agent with ethanol -wet bonding technique - an invitro study

Table 1. Bond strength values in Mpa

\begin{tabular}{|c|c|c|c|c|c|}
\hline \multicolumn{5}{|c|}{ Paired Samples Statistics } \\
\hline \multirow{2}{*}{ Pair 1 } & & Mean & N & Std. Deviation & Std. Error Mean \\
\hline \multirow{2}{*}{ Pair 2 } & WWB24 & 21.46037 & 100 & 3.031559 \\
\cline { 2 - 5 } & EWB24 & 54.47212 & 100 & 5.563151 \\
\cline { 2 - 5 } & WWB9M & 18.8125 & 100 & 1.48246 \\
\hline
\end{tabular}

Table 2. Paired samples test

\begin{tabular}{|c|c|c|c|c|c|c|c|c|c|}
\hline \multicolumn{10}{|c|}{ Paired Samples Test } \\
\hline & & \multicolumn{5}{|c|}{ Paired Differences } & \multirow[b]{3}{*}{$\mathrm{t}$} & \multirow[b]{3}{*}{ df } & \multirow[b]{3}{*}{ Sig. (2tailed) } \\
\hline & & \multirow[b]{2}{*}{ Mean } & \multirow[b]{2}{*}{ Std. Deviation } & \multirow[b]{2}{*}{ Std. Error Mean } & \multicolumn{2}{|c|}{$\begin{array}{l}95 \% \text { Confidence } \\
\text { Interval of the Difference }\end{array}$} & & & \\
\hline & & & & & Lower & Upper & & & \\
\hline Pair 1 & $\begin{array}{l}\text { WWB24- } \\
\text { EWB24 }\end{array}$ & -33.011750 & 6.566197 & 0.656620 & -34.314626 & -31.708874 & -50.275 & 99 & 0.000 \\
\hline Pair 2 & $\begin{array}{l}\text { WWB9M- } \\
\text { EWB9M }\end{array}$ & -22.06477 & 2.85068 & 0.28507 & -22.63041 & -21.49913 & -77.402 & 99 & 0.000 \\
\hline
\end{tabular}

\section{Discussion}

The seek for an artificial restorative material mimicking natural tooth both in function and aesthetics in the oral environment still remains a primary concern to the dentist which has led to the use of a number of restorative materials in dentistry. The science and technology of composite dental restorative materials have progressed significantly over the past 10 years. The concept of composite and bonding to tooth structure has led to major alterations in cavity preparation, with a general drift towards the increased preservation of healthy, natural tooth structure. In spite of the significant improvements in adhesive systems, the bonded interface remains the weakest area of composite restorations.

Due to complex chemico micromechanical bonding current composite materials fails to resist the effects of marginal penetration and the leakage of oral fluids as enamel has less than $1.00 \%$ of water content, hydrophobic resin worked well as long as they were restricted only to enamel. Dentin consists of 50\% volume of inorganic material $30 \%$ of organic and $20 \%$ volume of fluids. After acid etching, the demineralized dentin consists of $30 \%$ of collagen and $70 \%$ water [15]. Whenever a tooth is prepared with bur the organic and inorganic components form a smear layer on the tooth surface which is composed of hydroxyapatite and denatured collagen and bacteria [16]. Nakabayakshi, et al. [17] believed that hydrophobic resin infiltrated a surface layer of collagen fibres in demineralized dentin to form a hybrid layer consisting of resin infiltrated dentin between the adhesive and non-demineralized dentin. Initially during etch and rinse technique when etched dentin is dried using air way syringe bond strength is decreased because of the Collapse of collagen fibres. When water is removed, the collagen with fewer intrafibrillar spaces open for the penetration of the monomers. This dehydration permits additional hydrogen bonds to form between collagen, leaving no interfibrillar a space which results in decreased bond strength. The interfibrillar spaces can be expanded by refilling with water. In the early 1990s "wet" (or moist) bonding. technique was developed by Kanca to improve initial bond strength of etch and rinse adhesive. In this technique water is used as a solvent which permits to re expand the collapsed demineralized dentin matrices prior to resin infiltration, but water is not a proper solvent for resin monomer as resin monomers miscibility is limited in the water, resulting in the phase separation of hydrophobic resin [18]. The excess water causes sub optimal polymerization, nanoleakage and activation of matrix metalloproteinase which may all lead to biodegradation of resin dentin interface [2].
The use of adhesives on moist dentin is made possible by incorporation of organic solvents acetone or ethanol in the primer or adhesive, since these solvents displace water from the dentin surface and promotes the infiltration of resin monomer through the nanospaces of dense collagen web $[16,19]$.

The hydrophilic nature of the adhesive resin absorbs water leading to the plasticization effect reducing the mechanical properties of the resin component of adhesive joint Tto overcome the drawbacks of WWB and hydrophilic resin, EWB and hydrophobic resins were introduced by Tay, et al. Ethanol a water-based solvent used to support the demineralized dentin collagen fibrils and facilitate the penetration of BISGMA a hydrophobic adhesive resin into the ethanol saturated demineralized dentin. Ethanol saturated demineralized dentin matrices can be achieved by treating acid etched dentin surfaces with a series of increasing ethanol concentration $(50,70,80,95$, and $100 \% 3$ times each, for $30 \mathrm{~s}$ ), for $3-4 \mathrm{~min}$.As this process was tedious and time consuming, $100 \%$ ethanol for 1 min can be used which is called as "simplified ethanol wet bonding technique". This technique also can replace water while maintaining the collagen fibrils and promotes infiltration of resin monomers. When ethanol is mixed with the hydrophobic resin there is formation of hydrogen bonds between water and ethanol molecules which leads to better evaporation of water ethanol aggregate than plain water [10]. The principles of ethanol-wet-bonding are explained by using Hoy's triple solubility parameter theory [12].

The Solubility parameters for hydrogen bonding forces $(\delta \mathrm{h})$ can predict the nature of any solvents or resin's capability to re-expand a collapsed dried acid etched dentin. When demineralized dentin matrices are collapsed (dried dentin), to re expand matrices again, a solvent or resin monomer should have a higher hydrogen bonding force of more than $14.8(\mathrm{Jcm} 3)$ when ethanol was used as a substitute to rinse water from acid-etched matrices, the collapse of matrices was very less and resin infiltration into the hybrid layer appeared to be very high. But acetone has only $11\left(\mathrm{jcm}^{3}\right)$ which is not sufficient to cleave the interpeptide hydrogen bonding between the collagen fibrils. Later investigations confirmed that ethanol wet-bonding enhances resin infiltration which promotes higher penetration and bonding of resin to the tooth surface in comparison with conventional water wetbonding [12].

The rationale behind microtensile bond strength testing method is that the stronger the adhesion between tooth and biomaterial, the better it will resist stress imposed by resin polymerization and oral function. 
Pugal N (2019) Comparative evaluation of microtensile bond strength of resin based composite to dentin using an experimental neat-resin dentin bonding agent with ethanol -wet bonding technique - an invitro study

The samples of group 1(EWB)-1a,1b, group 2 (WWB)-2a,2b were etched and the groups $1 \mathrm{a}, 1 \mathrm{~b}$ were saturated in $100 \%$ ethanol for $60 \mathrm{sec}$ and blot dried. Two coats of the experimental neat resin are applied on to the ethanol saturated demineralized dentin surface. The experimental neat resin is prepared based on is used in group 1 [11]. In group 2a,2b ethanol based etch and rinse adhesive (3M Adaper single Bond 2) is used which consists of HEMA, BISGMA, Fillers, Ethanol, water, inititators. Resin composite build ups were done using (3M3SPE Filtek Z350 XT) made of BISGMA, UDMA, BISEMA-6, minimum amount of TEGDMA, Silica and light cured. Samples of $1 b, 2 b$ are immersed in artificial saliva. and were stored in this at $37^{\circ} \mathrm{C}$. The solution is changed periodically. All The samples were subjected to micro tensile bond strength testing and were viewed under SEM. The beam sticks has tooth on one side and the other half will be the composite. A digital calliper was used to measure the dimension of each specimen.

Microtensile bond strength was tested in a universal testing machine (INSTRON) in CIPET Guidy Chennai. Only group 1a, $2 \mathrm{a}$ is tested to check immediate bond strength the other groups $1 b, 2 b$ were immersed in artificial saliva for a period of nine months.

A separate fixture was made to grasp the beam sticks and the fixture is held on to the UTM machine in which the sticks were bonded to the test apparatus with cyanoacrylate resin. The sticks were held with the tweezer. These beams were stressed to fail under tension at a constant cross head speed of about $1 \mathrm{~mm} / \mathrm{min}$ until the sticks break and that particular point where the fracture occurred the values were noted in $\mathrm{MPa}$. All the fractured sticks were collected and placed separately and were coated with gold sputtering nanoparticles and later representative samples from each group was observed under scanning electron microscope to identify what type of fracture it is (adhesive, cohesive or mixed failure). SEM scans the surface of the samples with a focused beam of electrons and produces an image. Fractographical analysis were made. The samples of EWB showed fracture extending from the adhesive to composite or to dentin (mixed failures) while WWB group showed entirely between adhesive and dentin (adhesive failure). (Figures 1a,1b and 2)

\section{According to the statistical analysis paired t test were used}

For WWB (24hrs)-immediate bond strength values were 21.460; WWB-9 months -18.8125, EWB- immediate bond strength values were-54.47; EWB-9months-40.877

Std.deviation -WWB 24 hrs-3.0315; WWB-9months-1.4824, EWB-24hrs-5.5613; EWB 9 months -2.4097. There showed a decrease in bond strength after 9 months of storage in artificial saliva

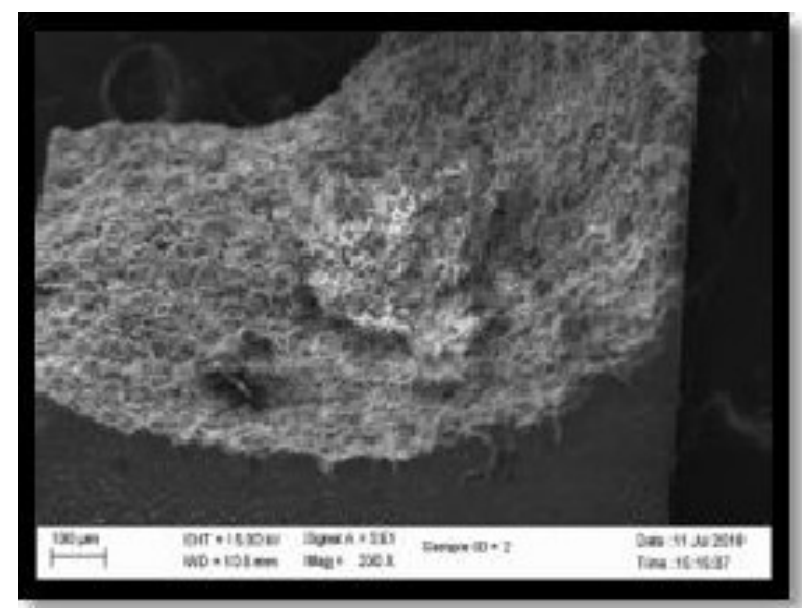

SEM-GROUP 1a IMMEDIATE MTBS

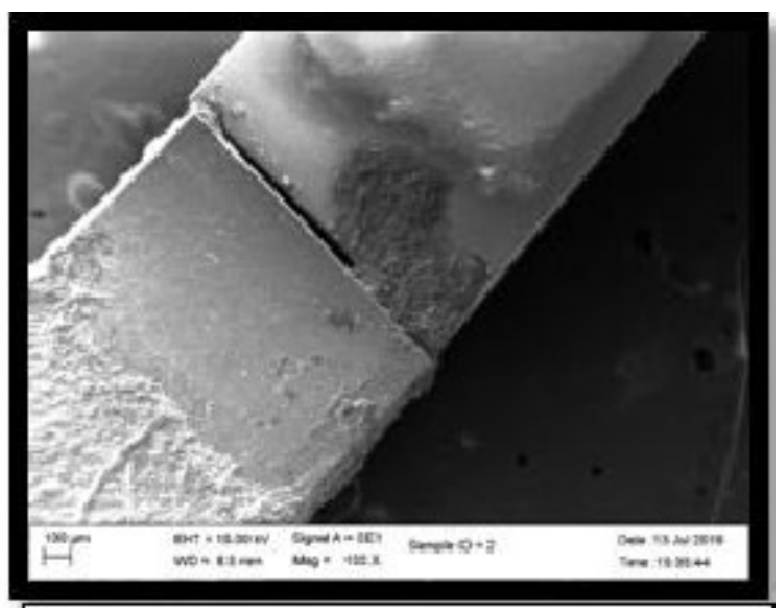

SEM-GROUP $1 \mathrm{~b}$ NINE MONTHS

Figure 1a,1b. Mean ethanol wet bonding strength recorded among the groups

Eeivb 24 nrs Ex ewo 9 months

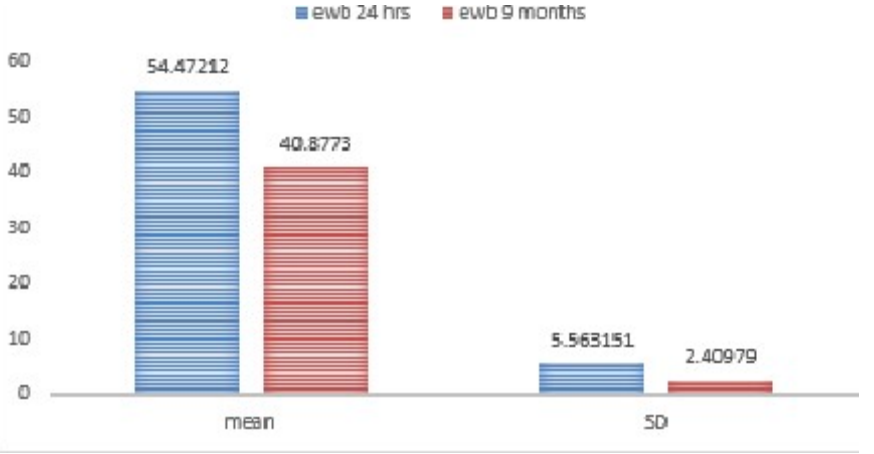

ETHANOL WET BONDING

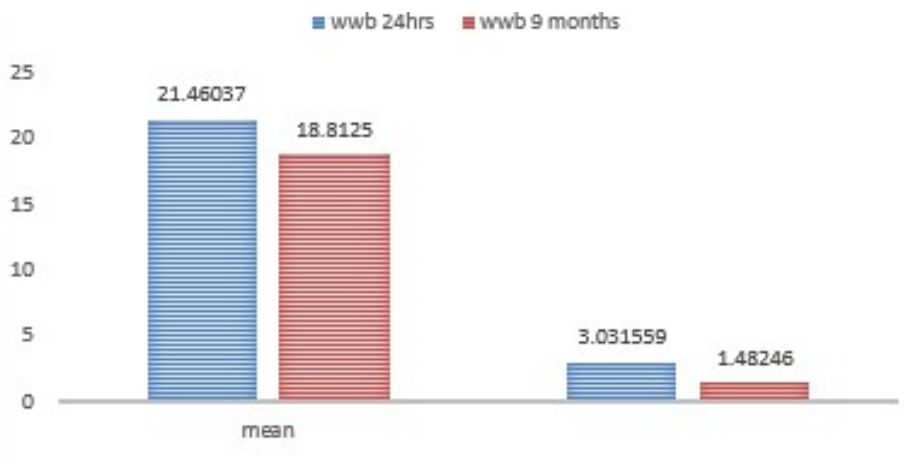

WATER WET BONDING

Figure 2. Mean water wet bonding strength recorded among the groups 
Pugal N (2019) Comparative evaluation of microtensile bond strength of resin based composite to dentin using an experimental neat-resin dentin bonding agent with ethanol -wet bonding technique - an invitro study

\section{Conclusion}

The simplified ethanol wet bonding technique shows improved microtensile bond strength in sound dentin. The advantage of the ethanol-wet bonding technique is that it can effectively allow less hydrophobic monomers into the dentine matrix, creating a more hydrophobic hybrid layer that could absorb less water over time. Thus ethanol wet bonding groupl showed better bonding than water wet bonding group 2 .

\section{References}

1. Pashley DH (2003) The evolution of dentin bonding. Dent Today 22: 112-114, 116, 118-119. [Crossref]

2. Kanca J (1992) Improving bond strength through acid etching of dentin and bonding to wet dentin surfaces. J Am Dent Assoc 123: 35-43. [Crossref]

3. Ekambaram M, Yiu CKY, Matinlinna JP (2015) An overview of solvents in resindentin bonding. Int J AdhesAdhes 57: 22-33.

4. Liu Y, Tjäderhane L, Breschi L, Mazzoni A, Li N, et al. (2011) Limitations in bonding to dentin and experimental strategies to prevent bond degradation. J Dent Res 90: 953-968. [Crossref]

5. Sadek FT, Pashley DH, Nishitani Y, Carrilho MR, Donnelly A, et al. (2008) Application of hydrophobic resin adhesives to acid-etched dentin with an alternative wet bonding technique. J Biomed Mater Res A 84: 19-29. [Crossref]

6. Ayar MK (2016) A review of ethanol wet-bonding: Principles and techniques. Eur $J$ Dent 10: 155-159. [Crossref]

7. Pashley DH, Tay FR, Carvalho RM, Rueggeberg FA, Agee KA, et al. (2007) From dry bonding to water-wet bonding to ethanol-wet bonding. A review of the interactions between dentin matrix and solvated resins using a macromodel of the hybrid layer. $\mathrm{Am}$ J Dent 20: 7-20. [Crossref]

8. Aggarwal V, Singla M, Sharma R, Miglani S, Bhasin SS (2016) Effects of simplified ethanolwet bonding technique on immediate bond strength with normal versus cariesaffected dentin. J Conserv Dent 19: 419-423. [Crossref]
9. Talungchit S, Jessop JLP, Cobb DS, Qian F, Geraldeli S, et al. (2014) Ethanol-wet bonding and chlorhexidine improve resin-dentin bond durability: quantitative analysis using raman spectroscopy. $J$ Adhes Dent 16: 441-450. [Crossref]

10. Yesilyurt C, Ayar MK, Yildirim T, Akdag MS (2015) Effect of simplified ethanol-wet bonding on dentin bonding durability of etchand-rinse adhesives. Dent Mater $J 34$ 441-448. [Crossref]

11. Ekambaram M, Yiu CKY, Matinlinna JP, King NM, Tay FR (2014) Adjunctive application of chlorhexidine and ethanol-wet bonding on durability of bonds to sound and cariesaffected dentine. J Dent 42:709-719. [Crossref]

12. Ayar MK, Yesilyurt C, Alp CK, Yildirim T (2014) Effect of ethanol-wet-bonding technique on resin-enamel bonds. J Dent Sci 9: 16-22.

13. Ayar MK (2014) Effect of simplified ethanol-wet bonding on microtensile bond strengths of dentin adhesive agents with different solvents. J Dent Sci 1-5.

14. Sadek FT, Braga RR, Muench A, Liu Y, Pashley DH, et al. (2010) Ethanol wet-bonding challenges current anti-degradation strategy. J Dent Res 89: 1499-1504. [Crossref]

15. Hashimoto M, Ohno H, Sano H, Tay FR, Kaga M, et al. (2002) Micromorphological changes in resin-dentin bonds after 1 year of water storage. J Biomed Mat Res 36: 306-311. [Crossref]

16. Hosaka K, Nishitani Y, Tagami J, Yoshiyama M, Brackett WW, et al. (2009) Durability of resin-dentin bonds to water- vs. ethanol-saturated dentin. J Dent Res 88:146-151. [Crossref]

17. Nakabayashi N, Nakamura M, Yasuda N (1991) Hybrid layer as a dentin-bonding mechanism. J Esthet Dent 3: 133-138. [Crossref]

18. Jain P, Stewart GP (2000) Effect of dentin primer on shear bond strength of composite resin to moist and dry enamel. Oper Dent 25: 51-58. [Crossref]

19. Li F, Liu X-Y, Zhang L, Kang J-J, Chen J-H (2012) Ethanol-wet bonding technique may enhance the bonding performance of contemporary etch-and-rinse dental adhesives. $J$ Adhes Dent 14: 113-120. [Crossref]

Copyright: (C2019 Pugal N. This is an open-access article distributed under the terms of the Creative Commons Attribution License, which permits unrestricted use, distribution, and reproduction in any medium, provided the original author and source are credited. 